\title{
Apresentação e panorama da tradução entre as línguas chinesa e portuguesa
}

O número temático "Especial China" desta Cadernos comemora os 500 anos da chegada do navegador português Jorge Álvares a Tamão (屯门 tunmen), região do Delta do Rio das Pérolas (珠江 zhujiang) em Cantão (广东 Guangdong). Esse contato foi intermediado por intérpretes chamados então de jurubaças, palavra de origem malaia jurubhasa, em que juru significa "mestre, perito" e baça [bhasa] "língua". Inicialmente, eles eram mestiços portugueses e malaios; mais tarde, portugueses e chineses convertidos ao cristianismo‥ Em 1582, chega a Macau a missão jesuítica protegida pela coroa Portuguesa que funda seminários ${ }^{2}$ e representa o marco da primeira fase da tradução sino-portuguesa (1582-1773). Desse período existe o registro de sete tradutores ${ }^{3}$. Foi no século XVII que surge o primeiro Dicionário português-chinês ${ }^{4}$ de Matteo Ricci e Michele Ruggieri ${ }^{5}$. Àquela altura, a baixa instrução dos jurubaças somada à pouca habilidade para o manejo interlinguístico, fez com que em 1627 fosse estabelecido o "Regimento da Língua da Cidade e dos Jurubaças menores e escrivães" para regulamentar a atividade

1 DALGADO, Sebastião Rodolfo. Glossário Luso-Asiático. Coimbra: Imprensa da Universidade, 1919.

2 JIN, Guoping; WU Zhiliang. 《东西望洋》Dōngxī wàngyáng [Em busca de história(s) apagada(s) pelo tempo]. Macau: Instituto da Educação Adulta, 2002.

3 Zhōngguó Fānyì Cídiăn [Dicionário de tradutores da China]. Pequim: China Translation \& publishing, 1988.

4 De acordo com Jin (2002, p. 33), até 1974 houve vinte e cinco versões de dicionários chinês-português e apenas treze edições foram publicadas. Somente em 1831 e 1833 foram lançados os dicionários português-chinês e chinês-português pelo Instituto São José em Macau. Conforme o pesquisador, nesta altura o português, a língua franca estabelecida pela missão jesuítica no Extremo Oriente, já tinha sido substituída pelas línguas inglesa e francesa. Os dicionários de Chen (ed.) (2001) e Wang; Lu (1997) de maior fôlego somente foram publicados no período do retorno da soberania de Macau à China em 1999.

5 RICCI, Matteo; RUGGIERI, Michele. Dicionário português-chinês. Macau/Lisboa/San Francisco: Biblioteca Nacional Portugal, Instituto Português do Oriente, Ricci Institute for Chinese-Western Cultural History, Universidade San Francisco, 2001. 
tradutória ${ }^{2}$. Nesses séculos de intercâmbios luso-chineses, diga-se de passagem, a qualificação e a carência de tradutores e intérpretes continua a ser um gargalo para a intensificação das respectivas relações.

A segunda fase áurea da tradução sino-lusófona ocorre com a proclamação da República Popular da China (1949). Para construir um país sob uma nova consciência revolucionária, o Partido Comunista Chinês empenhou esforços na formação política através de meios indiretos, que indicassem o engajamento de outros povos contra a opressão $0^{6}$ (vide a entrevista com Li Junbao, neste volume). Com esse intuito, é publicado O cavaleiro da esperança de Jorge Amado em 1953 e, entre 1959 e 1962, é lançada a Coleção de Clássicos Latino-americanos pela Editora do Povo, cuja apresentação enfatiza o caráter de "introduzir os Clássicos com teor revolucionário e crítica ao realismo. Quanto à literatura moderna, focar em obras que mostrem a luta do povo contra o colonialismo"7. Dentre os onze títulos, quatro obras brasileiras (tradução indireta) compõem a primeira série: $O s$ sertões de Euclides da Cunha (1959), Antologia poética de Castro Alves (1959), A hora próxima de Alina Paim (1958) e $A$ marcha de Afonso Schmidt (1960). Com o auge do acirramento do conflito ideológico sino-soviético em fins de 1950, a China passa a promover uma política de aproximação com a esquerda latino-americana ${ }^{8}$ : além do curso de espanhol estabelecido em 1952, envia uma turma para aprender português em Macau em fins de 1950 e abre dois cursos de Língua Portuguesa em Pequim em 1960 e 1961. A literatura da África de expressão portuguesa marcou presença com Antologia de Sincaia (1962), Antologia poética de Angola (1963) e Antologia e poemas de combate de Moçambique (1975). Um encarte mensal "Boletim Informação" no jornal 北京周刊 Beijing zhoukan é lançado em 1978 e encerra-se em 1979, devido à carência de tradutores 9 . Com as políticas de Reforma e Abertura em 1978, a China gradativamente ruma ao socialismo de mercado e inaugura-se a terceira fase de traduções sino-portuguesas a partir da década de 1980.

Em Macau, o padre Joaquim A. Guerra empreende um projeto audacioso da tradução do chinês para o português. São oito títulos de Clássicos chineses em edição bilíngue e notas críticas, publicados entre 1979 e 1987 pela editora Jesuítas

6 CHEN, Yantian; YUAN, Jinxiang (eds.). Zhōngguó fānyì cídiăn [Dicionário de Tradução da China]. Wuhan: Editora Educacional de Hubei, 1997, pp. 29.

7 CASTRO ALVES, A. F. Kăsītèluó •Āěrwéisī shī xuăn [Antologia poética de Castro Alves], tradução de Chen Yongyi alias Yiqian. Pequim: Editora do povo, 1959, s/p.

8 BECARD, Danielly Silva Ramos; LUZ, Arnaldo José da. "Presença da China na América Latina: contribuições para o desenvolvimento da Região". In Ciências \& Letras, 48, 2010, pp. 81.

9 Disponível em: <http://www.beijingreview.com.cn/rw/txt/2008-07/23/content_135528.htm>. Acesso em 26 de julho de 2008. 
Portugueses. Na década de 1990, o Instituto Cultural de Macau, o Instituto Português do Oriente (IPOR) e a Fundação Oriente, em colaboração com editoras da China continental, lançam 27 títulos em tradução direta do português para o chinês na Coleção Biblioteca Básica de Autores Portugueses.

$\mathrm{Na}$ China continental, 1980 é considerada a década de ouro do livro e é quando ocorre a "explosão" da literatura latino-americana. Nesse contexto, a Editora do Povo de Yunnan lança entre 1988 e 1997 a Coleção de Clássicos Contemporâneos da América Latina com 57 volumes, entre estes, seis títulos brasileiros, quatro de Jorge Amado, sendo Dona Flor e seus dois maridos o "carro-chefe" da série (vide Zhang, neste volume).

Segundo a totalização através de cruzamentos de dados (Vide Abi-Sâmara e Schmaltz, neste volume) foram publicados aproximadamente 125 títulos portugueses e 132 títulos brasileiros de 83 escritores lusófonos em língua chinesa, de 1953 a 2013, sendo 94 títulos literários. Os escritores mais publicados em língua chinesa são Jorge Amado, Paulo Coelho, Eça de Queirós e Machado de Assis, enquanto o livro com a maior tiragem foi $A$ escrava Isaura (1985), com 422.600 exemplares em apenas um mês, por duas diferentes editoras. $O$ sucesso da telenovela exibida em 1984 e o desígnio do Prêmio Nobel da Literatura para Gabriel Garcia Marques, em 1982, e para Octávio Paz, em 1990, suscitaram uma "febre sul-americana", alavancando na esteira o lançamento de títulos brasileiros ${ }^{10}$.

A partir de 1990, a mercantilização chega às editoras e a recepção da literatura de expressão portuguesa manteve-se tímida com uma ligeira elevação quando da conferência do Prêmio Nobel de Literatura a José Saramago em 1998. A apreciação de sua literatura ocorreu através da pena de um dos maiores tradutores literários da língua portuguesa Fan Weixin, galardoado com o Prêmio Lu Xun Arco Íris de Tradução Literária, atribuído pela Associação Chinesa de Escritores por Memorial do Convento (1998), bem como recebeu a Ordem do Mérito do governo de Portugal em 1997. Fan de 73 anos traduziu mais de uma dezena de títulos do português e é o único tradutor chinês que recebeu o prêmio de tradução pela Associação Paulista de Críticos de Arte em 1991. Yao Jingming ou Yao Feng como prefere ser chamado, obteve em 2006 a comenda Ordem Militar de Santiago de Espada do governo de Portugal em reconhecimento pela sua contribuição ao intercâmbio dos povos, este tradutor é responsável por quase duas dezenas de traduções. Pelo lado lusófono, António Graça de Abreu de 65 anos é o tradutor mais referenciado

10 TENG, Wei. 'Biānjìng'zhī nán: Lādīng Měi zhōu wénxué hànyì yǔ Zhōngguó dāngdài wénxué: 1949-1999 [Ao sul da "Fronteira": A tradução da literatura latino-americana ao chinês e a literatura contemporânea chinesa: 1949-1999]. Pequim: Editora da Universidade de Pequim, 2011, pp. 2. 
e reconhecido sinólogo. Em 1990, recebeu o Prêmio de Tradução da Associação Portuguesa de Tradutores e Pen Club por Poemas de Li Bai.

De 2000 em diante, a economia de mercado estabelece-se e as publicações voltam-se ao interesse do capital. Os livros de Paulo Coelho e Antônio Cury são os mais vendidos, junto ao Meu pé de laranja lima e Vamos aquecer o sol de José Mauro de Vasconcelos. De uma perspectiva histórica percebe-se uma relação estreita entre ideologia e linha editorial. Enquanto nos anos 1950-1970, o auge do período socialista, privilegiou-se edições com viés revolucionários em que encobria o sentimental, a partir de 1980, com a Abertura e a Reforma econômica chinesa publicam-se cada vez mais livros de interesse do mercado.

As relações entre o Brasil e a China vêm se dando desde 1879 e em 2010 comemorou-se o bicentenário da imigração chinesa ao Brasil. Apesar da presença crescente da literatura chinesa no maior país da América Latina a partir de 2004, ainda são raríssimas as traduções diretas do chinês para o português, não passando de 20 obras, sendo que a poesia e a prosa da Literatura Clássica chinesa configuram a maior parte dos títulos disponíveis. Esta situação tende a mudar com a crescente influência econômica e política da China somada à conferência do Prêmio Nobel de Literatura a Mo Yan. Em 2013, o mercado editorial brasileiro lançou Mudança de Mo Yan, tradução de Amilton Reis (Cosac Naify); Deixe-me em paz de Murong Xuecun, tradução de Márcia Schmaltz (Geração Editorial); Antologia da poesia clássica cbinesa, tradução de Ricardo Portugal e Tan Xiao (editora da UNESP) e, em 2014, a Antologia de poesia chinesa do século XX, tradução de Milena de Moura Barba (Annablume) para dizer apenas alguns que se tem notícia. Já o mercado editorial chinês neste ano publicou traduções diretamente do português como Alberto Caieiro, tradução de Min Xuefei (Editora Comercial), O Filho Eterno, tradução de Ma Lin (Editora do Povo) e Ensaio sobre a Lucidez, tradução de Fan Weixin (Thinkingdom), entre outros.

Enquanto que na China ocorre uma 'erupção vulcânica' de cursos de graduação em Língua Portuguesa (de dois na década de 1960, sete em 2005, vinte e dois em 2013 e previsão de trinta e dois até $\left.2015^{11}\right)$, nos países de expressão portuguesa existem apenas três instituições a oferecerem curso de graduação em Língua Chinesa. Embora haja a proliferação de Institutos Confúcio, estes não substituem a construção do campo de investigação e de formação pelas próprias instituições de ensino superior de expressão portuguesa. Espera-se que, num futuro breve, esta realidade possa mudar.

11 Disponível em: < http://noticias.sapo.pt/internacional/artigo/ensino-de-portugues-na-china-esta-em-fase-de-aperfeicoamento-academica_16381073.html>. Acesso em 05 de agosto de 2013. 
Neste "Especial China" recebemos um significativo número de preciosas contribuições de Portugal, China e Brasil. No artigo "A recepção das obras de Jorge Amado na China", de Pequim, Zhang Jianbo apresenta uma minuciosa pesquisa historiográfica acerca da tradução e da introdução das obras de Jorge Amado na China nos últimos cinquenta anos e explica porque Jorge é tão "amado" nesse país.

Seguindo a linha da história da tradução, de Macau, Raquel Abi-Sâmara e Márcia Schmaltz apresentam o escopo e os resultados iniciais do projeto de pesquisa no artigo "Tradução de poesia entre português e chinês: pesquisa e catalogação historiográfica na Universidade de Macau.” Mediante a coleta das bibliografias, as autoras se depararam com a complexidade da definição de quem é o tradutor de poesia chinês-português.

Também de Macau, a poetisa Han Lili apresenta-nos um dos intelectuais macaenses mais importantes da antiga possessão portuguesa no artigo "Contributo da adjetivação na construção da identidade macaense - estudo da obra Curiosidade de Macau Antiga de Luís Gonzaga Gomes".

Huang Lihai é criador de importantes conceitos poéticos como Geração de 1970, Geração Intermediária, a Escrita Poética Feminina e a Escrita Íntegra no círculo literário chinês. No artigo "A revista Homem e Poesia e a disseminação da poesia”, ele relata essa trajetória construída a partir de ideais e à memória de sua juventude. A Revista sobre sua liderança, constitui-se como contracorrente ao mainstream.

A partir de uma análise do contexto da sinologia e da educação brasileira nos últimos vinte anos, André Bueno relata "As dificuldades de uma tradução: um ensaio sobre o Sunzi bingfa 孫子兵法 e o contexto cultural brasileiro", que trata de sua tradução da obra chinesa mais publicada no Brasil. O filósofo propõe uma nova tradução ao título, descreve à negociação com a editora e ainda se debruça sobre o tratamento da linguagem na tradução, com um curioso desdobramento ao final do artigo.

Por uma perspectiva cultural sob o viés da Teoria da Relevância, Li Huang, no artigo "Uma análise das lacunas culturais entre chinês e português na tradução do romance Viver", analisa as escolhas lexicais e as estratégias empregadas na tradução desta obra. A autora conclui que a tradução não é apenas restringida pela capacidade do tradutor, mas também pelas diferenças linguística e cultural, especialmente a distância geográfica entre a China e o Brasil.

Em tom intimista, Paulo de Tarso Cabrini Junior retrata com sensibilidade a leitura de Poemas Clássicos Chineses (2012) no artigo "Sun Yuqi e Sérgio Capparelli: história de uma tradução". Inspirado pelo termo de uma flauta chinesa, o autor 
guia-nos por um interessante colóquio dos maiores poetas da dinastia Tang à filosofia daoísmo e ao poeta Camilo Pessanha.

Em "Poesia clássica chinesa - dinastia Tang: princípios e roteiro para uma antologia em português", o poeta Ricardo Primo Portugal expõe os desafios específicos na tradução da poesia clássica chinesa colocados por características da língua e pelo alto grau de codificação das formas. Contudo, ele buscou recriar o efeito dos poemas pela utilização de recursos sonoros e semânticos de nossa língua em Antologia da poesia clássica chinesa (2013), em cotradução com Tan Xiao.

De Pequim, Hu Xudong parte de sua própria experiência de tradutor como poeta para, no artigo "Traduzir a poesia brasileira", contar-nos de seu contato inicial com a língua portuguesa, refletir sobre os obstáculos e desafios enfrentados para a tradução de Vinícius de Moraes, João Cabral de Melo Neto e Carlos Drummond de Andrade. Também comenta sobre a recepção desses autores no círculo literário chinês e o porquê da dificuldade da introdução do concretismo na China.

E por falar em concretismo, voltamos ao Brasil. Diana Junkes Bueno Martha, no artigo "Poesia-Ideograma: A lua móbile de Li Bai reimaginada por Haroldo de Campos", tece algumas considerações sobre a tradução da poesia chinesa realizada pelo poeta e propõe uma leitura de um poema de Li Bai (Li-Po) que, segundo a autora, é uma homenagem à China e uma provocação ao leitor de língua portuguesa.

Na seção de traduções comentadas, começamos pela dinastia Tang, o período áureo da poesia clássica chinesa. Alberto Marsicano, Chiu Yi Chih, Chiu Si-Yuan brindam-nos com dois poemas de Li Bai em três diferentes estilos. Ao ser perguntado do porquê de fazer três versões de um mesmo poema, o citarista e poeta Marsicano, que há pouco nos deixou, justificou que não há 'a' forma verdadeira de traduzir um poema, mas várias, igualmente corretas.

Maurício Arruda Mendonça segue a escola haroldiana e traduz por via indireta "Dois poemas de Bai Juyi reimaginados em português". O contato de Mendonça com a poesia chinesa ocorre em meio a uma pesquisa sobre estética e poesia japonesa, momento em que o poeta tradutor é seduzido pelo 'poeta mago' Bai Juyi (Po Chü-I), um dos mais produtivos da dinastia Tang, consagrado ainda em vida também na Coreia e no Japão. Um de seus temas favoritos era o ócio, que acreditava ser uma forma de autocultivação.

Du Fu é, ao lado de Li Bai, o maior poeta da dinastia Tang. Apesar de renomado, sua poesia é menos conhecida no Ocidente talvez pelo tom amargo e realista, em que reflete forte preocupação social de um período de instabilidade. 
Atendendo ao nosso convite, António Graça de Abreu oferece-nos 'a tradução impossível' em "Oito poemas de Du Fu" com uma detalhada biografia do 'santo dos poetas' e o seu tempo.

Leandro Durazzo apresenta-nos a "Peleja entre dois mestres zen-budistas: poemas para o quinto Patriarca". A poesia budista desenvolveu-se a partir da introdução da religião no segundo século da era atual e consolidou-se na dinastia Tang, ao lado do confucionismo e do daoísmo. A poesia budista divide-se em duas vertentes: a religiosa e o estado de espírito contemplativo e de busca de harmonia, que inspirou grandes poetas chineses clássicos.

Também da dinastia Tang, Italia Bonadio traduz "A pura claridade" de $\mathrm{Du} \mathrm{Mu}$, poeta lírico narrativo, com grande influência dos poetas Li Bai e Du Fu. A tradutora relata de forma detalhada seu percurso tradutório para a tomada de decisão, fazendo interconexões com Alberto Caieiro e a Divina Comédia.

Sun Lidong traduz "Um apólogo", de Machado de Assis, que tem quatro obras publicadas em chinês. Sun comenta que a recriação do conto em chinês procurou espelhar - ainda que modestamente - a fluidez e, ao mesmo tempo, a ironia e a erudição do original, que se constitui numa tarefa desafiadora.

Como transição da literatura clássica ao Modernismo, Márcia Schmaltz traduz o prefácio de $O$ chamado em "Lu Xun e a anatomia de um povo". Lu Xun, expoente do movimento da Nova Literatura das primeiras décadas do século passado, é um dos fundadores do modernismo na China e um dos escritores do século 20 que deixou o maior volume de escritos, que gerou um campo de estudo literário próprio e exerceu influência sobre as gerações de escritores seguintes. Por visar a salvar o país, enriquecer a língua chinesa e promover a sua modernização, Lu Xun utilizava da tradução literal para educar as mentes da intelligentsia.

Seguindo a linha do tempo, Milena de Moura Barba apresenta os "Poemas de Zang Kejia e Ai Qing", autores engajados politicamente e sucessores diretos do movimento Nova Cultura e Quatro de Maio de 1919. Ambos são poetas do período da poesia narrativa engajada de 1930. Zang Kejia é conhecido como o poeta camponês e Ai Qing foi o primeiro poeta chinês a receber a distinção da Ordem das Artes e das Letras da França em 1985.

Neste "Especial China" não poderia faltar a literatura contemporânea chinesa, e os editores acolheram uma segunda colaboração de Italia Bonadio, que traduziu "A anunciação da morte do herói", do poeta Bei Dao, um dos poetas mais respeitáveis da cena literária chinesa a nível mundial, pertencente ao movimento da poesia nebulosa (também conhecida pelo movimento poético da Revista Hoje) de 1970 e 1980. Ao contrário da linguagem precisa, com viés de engajamento da 
geração anterior, o movimento da poesia nebulosa abusou da linguagem simbólica, figurativa e efeitos sinestésicos na forma, voltados ao eu-poético.

Fan Shan traduz "A flor mais linda do mundo" do português Francisco Mota, colunista da seção "gastronomias" no semanário português Avante. A justificativa da escolha de Fan pelo poema do autor fica evidente quando se acompanha a revista, por conter mais alimento à alma do que ao corpo.

Ana Cristina Alves, atenta à questão do feminino na China, traduz o ensaio "O Confucionismo nos Nossos Dias: Transmissão Sincera", de Chen Yun. A filósofa revela a preocupação com o estado da língua chinesa em Hong Kong. Os artigos originalmente publicados no jornal Minbao foram reunidos numa coletânea com o título sugestivo de 《急救中文》[Pronto-socorro à língua chinesa] (2012).

Fechamos este número especial com três entrevistas da vanguarda de tradutores chineses depois da proclamação da República Popular da China (1949). Estes contribuíram para a divulgação da literatura de expressão portuguesa na China, num período em que o planejamento de Estado regulamentava a vocação do indivíduo de acordo com a necessidade de desenvolvimento do país. Como alunos de um novo curso, enfrentaram dificuldades relacionadas ao contexto histórico de 1960, como a falta de material didático, o ensino mediado por intérprete e a conclusão do curso sob a adversidade do período.

A primeira entrevista é com o tradutor da primeira geração Li Junbao, formado em Língua Russa. Quando do surgimento do conflito ideológico sino-soviético no final de 1950, foi designado para a primeira turma de língua portuguesa na China. Li Junbao trabalhou por mais de trinta anos na saudosa Edições em Línguas Estrangeiras de Pequim e relata a Márcia Schmaltz sobre as primeiras traduções da língua portuguesa depois de 1949 e o novo paradigma editorial chinês.

Li Changsen, tradutor, professor e historiador, é entrevistado por Lurdes Escaleira. James Li, como é conhecido, testemunha importantes momentos da história do ensino da língua e cultura portuguesas na China e constitui-se como uma radiografia da vida de James Li enquanto tradutor, intérprete e jornalista que trabalhou em diferentes contextos e vários países de língua portuguesa. James Li foi coordenador e docente do Curso de Tradução e Interpretação Chinês-Português da Escola Superior de Línguas e Tradução do Instituto Politécnico de Macau.

A última estrevista é com Yu Huijuan, que dedicou toda uma vida à Rádio Internacional da China como tradutora e intérprete, jornalista, correspondente e, finalmente, diretora-chefe do departamento de português da Rádio. Depois de se aposentar, Yu Huijuan ocupou-se, por mais alguns anos, à tradução no Tribunal 
de Última Instância de Macau. Muitas de suas traduções são de obras brasileiras e trabalhou por diversas ocasiões em parceria com Fan Weixin.

Este Especial, dedicado aos 500 anos de relação luso-chinesa, acolheu artigos sobre os Estudos da Tradução desse par de línguas. A capa foi encomendada à xilogravurista Wang Yi, que gravou quatro retratos de escritores premiados do Brasil, China e Portugal. Esta edição não se esgota e esperamos que o volume possa inspirar mais investigações que impusionem a pesquisa. Desejamos uma boa leitura a todos.

Márcia Schmaltz

Organizadora 